Revista do CESP, Belo Horizonte, v.36, n.55, p. 29-47, 2016

\title{
O rizoma pós-moderno e a escrita heteronímica no Livro do Desassossego
}

\section{The postmodern rhizome and the heteronymic writing in the Book of Disquiet}

\author{
Arturo Diaz \\ Faculdade de Filosofia de Braga, Braga / Portugal \\ arturodiaz@live.com.pt
}

- Para o poeta Manuel Gusmão e o filósofo Gilles Deleuze

Resumo: Este breve ensaio focaliza dois tópicos e visa uma leitura deleuziana do Livro do desassossego. Em primeiro lugar, do ponto de vista da sua composição estrutural, o Livro é um rizoma pós-moderno, composto de fragmentos que se conectam entre si, diferenciando-se. Esta composição fragmentária exprime, por sua vez, uma outra cisão ontológica na personalidade plural e descentrada de Fernando Pessoa, gerada pelo movimento da Diferença interna. Esta abordagem pós-moderna da obra-prima pessoana resulta do génio intempestivo pessoano que soube assimilar certa tradição do século XIX, soube ousar experimentar novas possibilidades, no âmbito do modernismo de Orfeu, e abrir as novas clareiras de um tempo a vir, que configuram a nossa contemporaneidade do século XXI. Nesta dimensão intempestiva desse porvir pós-moderno, interessa-nos realçar certos sinais e sintomas, como a nossa leitura do drama em almas interactivas, a partir do movimento dessa diferença ontológica, pura intensidade diferenciante. Daí o jogo ideal das diferenças, no pensamento e na criação, desse drama estático e rizoma heteronímico. Tratase de um jogo ontológico em que, havendo lugar para o acaso, o aleatório e o devir-outros, se opera a cisão fractal da subjectividade. Neste jogo ideal das diferenças, que configuram a dramaturgia heteronímica, as multiplicidades 
virtuais (afectos, visões ou perceptos) atualizam-se na consciência fluida da singularidade-Bernardo Soares e inscrevem-se no plano da expressão.

Palavras-chave: pós-moderno; rizoma; diferença; devir; multiplicidade; virtual; singularidade.

Abstract: This short essay on The book of disquiet, from a Deleuzian's reading, focuses on two essential topics. Firstly, from the point of view of its structural composition, The book of disquiet is post-modern rhizome, for it consists of fragments that are connected to each other, but differing among themselves. This fragmentary composition expresses, in its turn, another ontological split in the plural and decentred personality of Fernando Pessoa that is generated by the movement of internal difference. This postmodern approach of The book of disquiet proceeds from the untimely genius of its author, who knew how to assimilate certain traditions of the nineteenth century; to dare to try new possibilities in modernism with Orpheus; and to open new clearings of a time to come, which represents our contemporary twenty-first century. In the untimely dimension of this postmodern future, we are interested in highlighting certain signs and symptoms from the movement of the ontological difference - a pure differentiating intensity - as it is done in our reading of the drama in interactive souls. Hence the ideal set of differences in thought and creation of the static drama and the heteronymic rhizome. This is an ontological set in which if there is space for chance, random and becoming-other the fractal breakup of subjectivity then operates. In this ideal set of differences that shapes the heteronymic dramaturgy, the virtual multiplicities (affects, perceptions or visions) update themselves on the fluid consciousness of the singularity that is Bernardo Soares and they are part of the plan of expression.

Keywords: becoming; difference; multiplicity; postmodern; rhizome; singularity; virtual.

Data de recebimento: 17 de dezembro de 2015

Data de aprovação: 5 de janeiro de 2016 


\section{O livro-rizoma e o laboratório experimental}

“A pós-modernidade configura-se como uma reacção cultural, representa uma ampla perda de confiança no potencial universal do projecto iluminista."

L. Chevitarese, "As 'Razões' da Pós-modernidade"

"O que temos aqui não é um livro mas a sua subversão e negação, o livro em potência, o livro em plena ruína, o livro-sonho, o livro-desespero, o antilivro, além de qualquer literatura. O que temos nestas páginas é o génio de Pessoa no seu auge."

Richard Zenith, Introdução ao Livro do desassossego

Vamos, por conseguinte, tentar pensar o conceito de pósmodernidade no Livro do desassossego, a partir de duas ideias fundamentais: primeiro, na própria organização caótica do Livro como um rizoma de conexão múltipla e heterogénea de fragmentos textuais; depois, na própria fragmentação ontológica ou cisão fractal do sujeito plural, na sua dispersão e errância nomádica nas sensações verdadeiras, após ter passado por um processo de despersonalização e dissolução da sua identidade substantiva e molar, processo esse gerado pelo movimento da diferença interna, intensiva.

Não obstante Bernardo Soares considerar esses fragmentos, que compõem a sua obra, um refugo, cacos e um intervalo, estamos perante a obra maior de Pessoa, naquele sentido de work in progress, pelo que ela tem de experimental e de intuições intempestivas sobre a pós-modernidade que estamos vivendo e nos afecta. De facto, a tese mais afirmativa e contundente sobre o Livro foi exposta no ensaio do filósofo José Gil, Fernando Pessoa ou a metafísica das sensações (1987), quando nos diz estarmos perante um laboratório experimental, em que a matéria-prima do ofício poético-artístico são as sensações, que ele desfia nas suas análises microscópicas. Neste processo experimental, não só a consciência imanente e imediata da sensação gera o heterónimo, como surgem novos órgãos intensivos nesse corpo fluido e plástico, intenso, intensivo, que é o plano de consistência, onde Bernardo Soares constrói e agencia o seu corpo-sem-órgãos virtual.

Longe estamos nós das posições que vêem no Livro do desassossego um diário confessional, num registo poético. Essa dimensão 
é sustentável pelo próprio Bernardo Soares ao falar das suas Confissões e da sua autobiografia sem factos, tal é a recorrência obsessiva do eu ao longo do Livro. Pensamos, porém, que essa insistência no eu instaura uma repetição diferenciante, um autêntico devir-outros. O eu de Bernardo Soares não é uma identidade substantiva solipsista, imune aos devires do mundo, nem o sujeito kantiano das sínteses, nem uma pessoa regida pelas escalas molares da representação; o eu soaresiano é, para utilizarmos uma expressão deleuzina de inspiração bergsoniana, uma multiplicidade virtual de sensações, ideias; afectos, perceptos e acontecimentos ou devires.

A actualização dessa multiplicidade virtual, no plano da expressão escrita e na consciência larvar do esteta-sonhador, determina a génese do heterónimo latente. Assim, do ponto de vista ontológico, o que é primeiro, em Bernardo Soares, é a tal Diferença interna, diferença diferenciante e pura intensidade virtual, que Deleuze vislumbrou no génio de Marcel Proust e Virginia Woolf. Bernardo Soares tem uma identidade, mas essa identidade é plural e descentrada, como sabemos, e um efeito do movimento da interna Diferença constitutiva. Podemos acrescentar que Bernardo Soares é uma figura intervalar entre o sonho e a vigília e uma singularidade plural, serial e descentrada pelo movimento da Diferença interna, que resulta da comunicação das séries de sensações, visões e audições; palavras, frases e ritmos. Em última instância, o eu é um dispositivo de forças que resulta do espelhamento de outras forças heterogéneas, que ele capta,forças essas que o nómada contemplativo extrai do mundo e exprime nos regimes de signos-partículas.

É neste contexto que o próprio título da obra tem um cunho marcadamente pós-moderno: o desassossego soaresiano é muito mais que um estado subjectivo ou existencial de inquietação, angústia e desespero; o desassossego exprime, justamente, enquanto passagem e intervalo, esse movimento do sentido da Diferença interna, o movimento próprio das multiplicidades virtuais: sensações, sonhos; afectos e perceptos; acontecimentos e devires; frases, ritmos e intensidades prosódicas. Trata-se de um desassossego ontológico que exprime o movimento das singularidades nómadas no campo transcendental do pensamento e do sentir criador de novas possibilidades de vida. Essas multiplicidades puramente virtuais e intensivas actualizam-se de dois modos, através do processo da coalescência bergsoniana: actualizam-se na consciência larvar do esteta-sonhador, Bernardo Soares, e no plano da expressão 
escrita. Assim, o desassossego exprime o puro movimento do deviroutros, através dessa ritournelle do eterno retorno, que consiste na escrita e no estilo como variação contínua de singularidades. Como precisa Pedro Eiras, "Pessoa não cria a heteronímia como contrária à sinceridade: descobre que toda a escrita é heteronímica, incluindo a assinada por um «Fernando Pessoa» que aliás "não existe, propriamente falando", diz Campos (1997, p. 75)" (EIRAS, 2005, p. 208). Na realidade, Bernardo Soares, mais do que devir-outros, abrindo o limiar da heteronímia, devém sobretudo animal-impercetível-intenso-mulher, dada a sua condição de nómada da consciência de si e de transeunte de tudo.

Daí todo um teatro ontológico no Livro do desassossego com os seus dinamismos espácio-temporais. Esses dinamismos exprimem o movimento de actualização das referidas multiplicidades virtuais na consciência larvar do esteta-sonhador e no plano de expressão escrita. Por isso, em Bernardo Soares, podemos afirmar o primado ontológico do ser do devir, do ser que se diz do devir, no sentido espinosista em que podemos dizer que os modos também podem afectar a substância finita. Mais do que toda a cartografia afetiva do pathos finissecular e do existencialismo ateu, o desassossego de Bernardo Soares tem um valor ontológico: exprime esses dinamismos e processos que afectam o ser na génese do sentido ou do acontecimento, como um devir incorporal impassível. Bernardo Soares devém-paisagem-mundo frequentemente sentado na sua cadeira de sonhador, numa génese estática ontológica, através dos agenciamentos coletivos de enunciação.

Não obstante vincarmos a tese de uma crise na modernidade, como projecto revisível e inacabado, vivemos numa época em que os sinais da incerteza, da descontinuidade, da fragmentação, do contingente, do caos, da perda de referências e dos valores configuram uma pós-modernidade, como reacção cultural aos desastres da utopia da razão universal e do sonho iluminista. A descrição da nova conjuntura e idiossincrasia por David Harvey é, a este propósito, pertinente: "o pós-modernismo nada, e até se espoja, nas fragmentárias e caóticas correntes de mudanças, como se isso fosse o que existisse." (HARVEY, 1994, p. 49). E, de facto, podemos dizer que essa fragmentação, descontinuidade do fio narrativo e (aparente)sensação de caos, são três traços característicos da pós-modernidade que perpassam o nosso Livro do desassossego e, nesse sentido, sobressai o génio intuitivo e intempestivo de Bernardo Soares que viveu e soube dar expressão à nossa contemporaneidade, também 
ela marcada pelo dinamismo das multiplicidades, num jogo ideal de diferenças que comunicam, transversalmente por ressonâncias: "Nestas impressões sem nexo, nem desejo de nexo, narro indiferentemente a minha autobiografia sem factos, a minha história sem vida. São as minhas Confissões, e, se nelas nada digo, é que nada tenho que dizer." (SOARES, 1998, p. 54).

Neste sentido da pós-modernidade, e no seguimento da tese de José Gil, pensamos que o Livro do desassossego é um plano de composição estética consistente, um ser de sensação heterogéneo, composto por afectos (devires), perceptos e conceitos. Como sabemos, a sensação é uma unidade psico-estética complexa que se decompõe em ínfimas sensações, conforme o grau de acuidade da sua análise pelo intelecto expressivo. A sensação metafísica que nós privilegiamos é o desassossego ativo e criador, decorrente do mistério de existir no mundo. Para Bernardo Soares que ousa descascar as sensações até Deus e Caeiro, para quem os pensamentos são sensações, há uma relação de imanência entre as sensações, a consciência e a sua expressão. Nesta imanência, já não há aquela dissociação, inerente à fórmula fingir é conhecer-se, entre o pensar e o sentir, tão frequente no Pessoa ortónimo. Na imanência entre corpo escrevente e linguagem, as sensações nascem literárias, como num processo de automatismo psíquico, porque não há lugar para as mediações categoriais e representativas: "Sensações nascem analisadas./ Requinte entre a sensação e a consciência dela, não entre a sensação e o "facto" (SOARES, 1998, p. 498).

Podemos, agora, sublinhar a ideia de que, do ponto de vista da sua composição estrutural e do seu funcionamento genético, o Livro do desassossego é um rizoma pós-moderno, tal é a impressão de caos e da (aparente) falta de nexos de sentido que ressaltam da sua primeira leitura. Acresce a impressão de, nessa leitura propedêutica, entrarmos num verdadeiro labirinto de bifurcações e numa floresta de ramificações em que se cruzam vários planos. É como se o Livro, do ponto de vista da sua incessante reescrita textual, fosse um palimpsesto com camadas sobrepostas de sentido e um work in progress que não tem princípio nem fim, nem eixo estruturante e fundador de sentido, tal como as figuras pós-modernas do rizoma e da chaosmose.

No entanto, apesar dessa sensação de caos textual e de fragmentação ontológica decorrente da primeira leitura, há um sentido recorrente que se extrai: o da génese estática ontológica do nómada 
da consciência de si, capaz de devir-outros sur place, através do acto de sonhar. Diz Bernardo Soares sobre a composição estrutural e o funcionamento do texto-rizoma, palimpsesto, labirinto de bifurcações e floresta de ramificações, onde o sentido prolifera, disseminando-se. E mais do que o esforço hermenêutico de aceder ao sentido originário do texto matricial, importa entrar no regime do ser unívoco da imanência através de aproximações laterais: "Tudo quanto o homem expõe ou exprime é uma nota à margem de um texto apagado de todo. Mais ou menos, pelo sentido da nota, tiramos o sentido que havia de ser o do texto; mas fica sempre uma dúvida, e os sentidos possíveis são muitos." (SOARES, 1998, p. 164).

A própria composição fragmentária do Livro, sem um eixo fundador ou matriz originário do sentido, permite que qualquer fragmento se conecte com qualquer outro, assim como possibilita a conexão entre variados regimes de signos: os signos mundanos, os amorosos, os sensíveis e os estéticos. Assim, a dimensão rizomática pós-moderna do Livro implica duas propriedades, a conexão entre os fragmentos e a multiplicidade dos regimes de signos. O rizoma é justamente uma multiplicidade composta de dimensões, direcções e trajectos intensivos de sentido, que não começam nem acabam, porque, nesse milieu imanente, tudo recomeça sem cessar, num perpetuum mobile. Todo o começo é impensável, imemorial e virtual, porque, de certo modo, já se está na imanência, nesse meio intensivo, onde as coisas pegam e ganham velocidade. As sensações, as emoções poéticas, os sonhos, os afectos e os perceptos são essas dimensões do rizoma inscritas no Livro do desassossego, como linhas de fuga, linhas de vida e criação:

À la différence des arbres et de leurs racines, le rhizome connecte un point quelconque avec un autre point quelconque, et chacun de ses traits ne renvoie pas nécessairement à des traits de même nature, il met en jeu des régimes de signes très différents et même des états de non signes. Le rhizome ne se laisse ramener ni à l'Un ni au multiple... Il n'est pas fait d'unités, mais de dimensions, ou plutôt de directions mouvantes. Il n'a pas de commencement ni de fin, mais toujours un milieu, par lequel il pousse et déborde. Il constitue des multiplicités. (DELEUZE; GUATTARI, 1994, p. 31) 
Acresce que a pós-modernidade do Livro do desassossego (1997) decorre também do facto de estarmos perante uma obra cujos dinamismos composicionais e genéticos configuram um chaosmos. Como sublinha Deleuze na Logique du sens, não se coloca o problema da alternativa entre o sentido já formado e o caos informe do non sens (disjunção exclusiva), mas da afirmação da coexistência das singularidades, nómadas e pré-individuais, num plano de composição virtual, planómeno ou "chaosmose" (disjunção inclusiva):

Nous ne pouvons accepter l'alternative qui compromet à la fois la psychologie, la cosmologie et la théologie tout entières: ou bien des singularités déjà prises dans des individus et personnes, ou bien l'abîme indifférencié. Quand s'ouvre le monde fourmillant des singularités anonymes et nomades, impersonnelles, pré-individuelles, nous foulons enfin le champ du transcendantal. (DELEUZE, 1997, p. 125)

O problema que aqui se coloca, e de que o próprio Bernardo Soares tem consciência, é o de aceder e entrar nesse campo transcendental das singularidades nómadas e pré-individuais, para poder começar a pensar, sentir e criar no regime das multiplicidades, no regime da imanência e do tal plano de composição consistente e heterogéneo de sensações e emoções poéticas; afectos e perceptos; acontecimentos e devires. Por isso, não se trata de colocar o falso problema da disjunção entre o sentido pré-formado da doxa ou o abismo do non-sens, mas de afirmar a disjunção inclusa num mundo virtual ou num universo ficcional, engendrado a partir do caos e que se erige como Chaosmos, composição estética do caos, composto de visões, perceptos e afectos ou devires, tal como o Livro do desassossego: 'L'art n'est pas le chaos, mais une composition du chaos qui donne la vision ou sensation, si bien qu'il constitue un chaosmos, comme dit Joyce, un chaos composé -non pas prévu ni preconçu." (DELEUZE; GUATTARI, 2011, p. 204-295)

O sentido é extraído justamente de um caos de composição fragmentária, desconexa e ilógica, própria dos devaneios e dos sonhos de Bernardo Soares. Os sonhos são multiplicidades virtuais compostas de partículas fractais efémeras que cintilam no inconsciente e cuja duração é menor que a do mínimo tempo pensável. Relevam, por isso, de um princípio de indeterminação e de inconsciência. Bernardo Soares 
mergulha nessa região do inconsciente diferencial e explora o virtual subliminar de estados de consciência microscópicos, para daí extrair o sentido, os acontecimentos e os devires.

A chaosmose, de que falava James Joyce, além de apontar para um paradigma estético pós-moderno,é uma figura do inconsciente diferencial, enquanto produtor de sentido e condição do devir-outros, no plano de consistência do corpo-sem-órgãos. Os devaneios soaresianos aproximam a sua consciência desse universo onírico inconsciente povoado de partículas virtuais, algumas das quais emergem à superfície do plano de expressão. Nessa superfície metafísica, engendra-se o sentido: o sentido é o acontecimento e o acontecimento é toda a série de devires -devir-paisagem; devir-mulher; devir-sonho- da singularidade Bernardo Soares.

Por isso o Livro do Desassossego, enquanto rizoma, move-se efectivamente num novo paradigma estético pós-moderno que Guattari descreveu em termos de chaosmose. Aqui, a chaosmose não tem o sentido propriamente cosmológico relativo ao universo ordenado por uma inteligência ou racionalidade superior, mas indica o processo de génese do sentido a partir do inconsciente onírico diferencial de PessoaBernardo Soares. Neste paradigma, a produção do sentido faz-se por comunicação de séries divergentes de palavras, frases, intensidades prosódicas, ritmos; gestos, cores, sons e ressonância em certos pontos singulares que se movem. Há aí, no texto soaresiano e no seu corpo escrevente, ressonâncias entre sensações heterogéneas e movimentos forçados, todo um conjunto de dinamismos espácio-temporais.

$\mathrm{O}$ agente do movimento do sentido é o precursor obscuro, a entidade virtual; o tal sentiendum ou insensível sentido, que é a singularidade, ou a case vide lacaniana 'qui manque à sa place comme à sa identité'. Por sua vez, o sentido não deriva de uma ordem ou harmonia pré-estabelecida, mas de uma efectiva produção que extrai do caos do inconsciente diferencial os acontecimentos e devires, ou seja, o sentido através de concreções e preensões das singularidades moleculares em escalas de maior dimensão.

Bernardo Soares chega mesmo a traçar uma linha de coupure do caos indiferenciado das opiniões empíricas (doxa) para poder pensar no plano de imanência e criar no plano de consistência e de composição estética povoado de signos, entidades virtuais e Ideias estéticas, afectos e perceptos. Nesse plano de imanência, plano de consistência das sensações 
heterogéneas, ele pode devir-mulher-navio-página, traçando a tal linha de fuga abstrata no pensamento que o conecta com o dehors. Esse devir passa por uma intensificação do corpo empírico-transcendental de Bernardo Soares, constituído por zonas de indiscernibilidade objetiva, espaços vazios, onde o sentido-acontecimento circula. Em cada zona de indiscernibilidade, há um ponto singular constelado por pontos comuns. É através do domínio experimental dessa técnica do sonhar, enquanto viagem nas sensações verdadeiras, que ele pode devir-outros:

Sim, sonhar que sou por exemplo, simultaneamente, separadamente, inconfusamente, o homem e a mulher dum passeio que um homem e uma mulher dão à beirario. Ver-me, ao mesmo tempo, com igual nitidez, do mesmo modo, sem mistura, sendo as duas coisas com igual integração nelas, um navio consciente num mar do sul e uma página impressa dum livro antigo. Que absurdo que isto parece! Mas tudo é absurdo, e o sonho é o que o é menos. (SOARES, 1998, p.172-173)

\section{A pluralidade ontológica}

"A única realidade para mim são as minhas sensações. Eu sou uma sensação minha."

Bernardo Soares, "Ideias metafísicas do Livro do desassossego", p. 507

"Criei em mim várias personalidades. Crio personalidades constantemente. Cada sonho meu é imediatamente, logo ao aparecer sonhado, encarnado numa outra pessoa, que passa a sonhá-lo, e eu não."

(LD, f. 299, p. 283)

Afinal, essa composição rizomática, caótica e fragmentária do Livro do desassossego acaba por ser a expressão de uma cisão ontológica que ocorreu na personalidade de Fernando Pessoa e que Bernardo Soares repete, ad modum sui, descrevendo os seus processos genéticos. Essa expressão da cisão ontológica é virtual, uma espécie de anterior simultâneo, uma vez que coexiste com o ato de escrita diferenciador e heteronímico. Não vamos aqui descrever essa teoria complexa da 
heteronímia que Pessoa encenou em inúmeras cartas a João Gaspar Simões e Adolfo Casais Monteiro e que tem sido lucidamente pensada por Jorge de Sena (1982), Eduardo Lourenço (1993), Teresa Rita Lopes (1985) e José Gil (1987).

Importa, porém, salientar que essa fragmentação da identidade resultou de processos e técnicas que o nosso Pessoa-Bernardo Soares cultivou com esmero e prudência, lucidez e cálculo irónico, até se converterem em automatismos psíquicos, no plano do pensamento e da criação. Estamos a pensar concretamente na análise abstracta das sensações pelo intelecto expressivo, e na técnica do sonho, essa viagem imóvel nas sensações verdadeiras, sensações originárias e virgens, não contaminadas pela cultura e pelo estado de não-inscrição indiferenciadora da doxa. Estes processos que acabámos de referir encontram-se na origem do desdobramento da consciência pessoana e da consequente despersonalização. A consciência da sensação pelo intelecto expressivo gera o desdobramento do pensar e do sentir da personalidade e a consequente teoria do fingimento poético. Entra-se assim no limiar da heteronímia, através do devir-outros da singularidade nómada, Bernardo Soares.

Deu-se efectivamente uma fragmentação ontológica em Pessoa, produzida pelo pensamento abstracto e pela escrita heteronímica, porque o seu ser é fractal, emite partículas virtuais a uma velocidade absoluta. Podemos dizer que cada uma dessas partículas virtuais, que emerge do inconsciente diferencial produtor de sentido, é uma singularidade e um heterónimo latente, na composição rizomática dos movimentos desterritorializantes do Livro do desassossego. Digamos que o tal drama em gente sem actos, drama em almas interactivas constitui um rizoma heteronímico de proliferação de singularidades pré-individuais, em que se podem avaliar as relações interpessoais, mas sobretudo as poéticas, como expressões singulares de modos de sentir e ver o mundo.

Bernardo Soares viaja imóvel nas sensações, sonhando, e ao sonhar entra num devir-paisagem de campos e cidades, de vários países. Nessa viagem de sonho, opera-se o devir-imóvel, a génese estática ontológica que permite viver, sentir e ver mais, em menos tempo. No teatro do ser soaresiano, constelado de partículas fratais, a meta-experiência da intensidade diferencial dá-se num curto espaço de tempo, um mínimo de tempo pensável, mas os seus efeitos incorporais impassíveis afectam o corpo, tantas vezes dominado pelo cansaço, o 
tédio e o desassossego: "Cada vez que viajo, viajo imenso. O cansaço que trago comigo de uma viagem de comboio até Cascais é como se fosse o de ter, nesse pouco tempo, percorrido as paisagens de campo e cidade de quatro ou cinco países." (SOARES, 1998, p. 283).

Acontece, porém, que Bernardo Soares prolonga a sua metaexperiência mental e afectiva de devir nómada sur place. Ele concebe-se e imagina-se vivendo em cada casa por que passa, extraindo desse viver modos de sentir a alegria, o tédio e a saudade. Ele vive essa génese estática ontológica, porque devém-imóvel e sente as sensações imanentes. Ocorre nele uma experiência do excesso, porque ele vive e sente na imanência, no exercício transcendental das suas faculdades da alma. Ele fala mesmo nessa paradoxal colheita dolorosa e feliz, porque ele extrai o sentido, o devir, as afecções da alma e os perceptos, a partir dos dados empíricos: "De modo que todas as minhas viagens são uma colheita dolorosa e feliz de grandes alegrias, de tédios enormes, de inúmeras falsas saudades." (SOARES, 1998, p. 283).

Ele vai mais longe no seu devir-outro porque não se limita a viver nessas casas. Ele vive a vida de cada pessoa que habita essa casa; ele vive as vidas diferentes ao mesmo tempo, porque, nesse plano de consistência do heterogéneo intensivo, consegue sentir ao mesmo tempo sensações diversas, vendo-as por fora e sentindo-as por dentro. Entra, por assim dizer num agenciamento coletivo de enunciação ao devir-todo-o-mundo, sustentado por um plano de imanência, plano de consistência e de coexistência de sensações heterogéneas. Nesse plano de consistência, processa-se a sua dispersão ontológica, através de linhas de fuga compostas de partículas virtuais, como veremos, e a errância nomadológica do sentido:

Depois, ao passar diante de casas, de vilas, de chalés, vou vivendo em mim todas as vidas das criaturas que ali estão. Vivo todas aquelas vidas domésticas ao mesmo tempo. Sou o pai, a mãe, os filhos, os primos, a criada e o primo da criada, ao mesmo tempo e tudo junto, pela arte especial que tenho de sentir ao mesmo [tempo] várias sensações diversas, de viver ao mesmo tempo -e ao mesmo tempo por fora, vendo-as, e por dentro sentindo-as -as vidas de várias criaturas. (SOARES, 1998, p. 283). 
Assim, a partir do plano de consistência e de coexistência de sensações heterogéneas ou almas interactivas, ele pode criar, inventar várias personalidades que são os heterónimos virtuais, ainda não nitidamente diferenciados, como na poesia das Ficções do interlúdio. Cada sonho seu, modo de sentir e viajar nas sensações, encarna numa outra personalidade heteronímica, que afirma a autonomia expressiva desse sonho. Já não é o sujeito e a pessoa que sustentam e são afectadas pelos devires, mas uma singularidade nómada, pré-individual e uma multiplicidade intensiva que se desloca e flui nesse drama em gente sem atos ou no teatro do ser plural. Tudo acontece involuntariamente, como que por automatismo psíquico, tal é a versatilidade do domínio da técnica da escrita heteronímica e da arte de sonhar, nesse plano consistência do heterogéneo e de composição criativa: "Criei em mim várias personalidades. Crio personalidades constantemente. Cada sonho meu é imediatamente, logo ao aparecer sonhado, encarnado numa outra pessoa, que passa a sonhá-lo, e eu não.” (SOARES, 1998, p. 283).

Para criar várias vidas autónomas e diferentes, os heterónimos, teve que destruir, desconstruindo e dissolvendo pelo movimento da diferença interna, a sua identidade subjectiva, molar, macro-representativa, através do pensamento visual, abstracto e analítico das sensações, assim como da técnica do sonho. A génese do campo heteronímico povoado de virtualidades, que são os heterónimos, implica também a construção de um fora de todas as multiplicidades, o tal espaço, spatium intensivo de reversibilidade entre o dentro e ofora e de coalescência entre o virtual e o atual, que constitui o plano de consistência das diferenças heteronímicas.

A génese heteronímica implica também um teatro ontológico com as suas dramatizações, os dinamismos espácio-temporais, que dão conta da actualização das virtualidades do sonho numa diferença heteronímica, um heterónimo, um ator, enquanto figura singular de devir-outro. Cada actor representa uma peça, encarna dinamismos espácio-temporais específicos, conforme a ideia, a sensação e a visão virtual que se actualizam no plano de expressão imanente e na consciência sonhadora do sujeito larvar, a tal singularidade plástica e fluida. Esta passagem é crucial porque define o fora de Bernardo Soares como esse plano de consistência do heterógeneo intensivo, capaz de suportar as meta-experiências das faculdades da alma; precisa também o sentido do devir-eu como experiência singular (haecceitas) das multiplicidades intensivas, configuradoras desses dramas estáticos em almas: "Para criar, 
destruí-me; tanto me exteriorizei dentro de mim, que dentro de mim não existo senão exteriormente. Sou a cena viva onde passam vários actores representando várias peças." (SOARES, 1998, p. 284).

Afinal, a pluralidade ontológica pós-moderna e virtual de Bernardo Soares, como efeito de uma diferenciação interna, aboliu a identidade solipsista e imobilista das macro-representações. Como muito bem viu David Hume, a identidade é um efeito e uma construção que resulta da contracção de hábitos associativos. Essa identidade plural do polimorfo Bernardo Soares resulta do hábito contemplativo que contrai e condensa as singularidades. Além da sua vocação para habitar a imanência absoluta, construindo a pura exterioridade, como veremos, há nele uma forte tendência para devir-outro, permanentemente, a começar pelo seu devir-paisagem. Efetivamente, para Bernardo Soares viver é ser outro, através de um processo de despersonalização e desdobramento da singularidade nómada.

Com efeito, numa certa indiferença, sem esperança nem desespero, a vida é para ele uma simples exterioridade, efeito da distância gerada pelo movimento da Diferença interna. A vida é como um quadro onde decorre o espectáculo, ao qual ele assiste como num drama estático de inspiração simbolista, o tal teatro do ser de que fala Teresa Rita Lopes (1985); é também um bailado sem nexo, uma espécie de dança mental que exprime os sonhos e devaneios, na incoerência lógica deste Livrorizoma composto de fragmentos:

Para mim, que hoje não espero nem desespero, ela é um simples quadro externo, que me inclui a mim, e a que assisto como um espectáculo sem enredo, feito só para divertir os olhos -bailado sem nexo, mexer de folhas ao vento, nuvens em que a luz do sol muda de cores, arruamentos antigos, ao acaso, em pontos desconformes da cidade. (SOARES, 1998, p. 200)

Podemos mesmo afirmar que, a partir de uma ontologia da diferença interna e do ser que se diz do devir, há uma relação de imanência entre o ser plural e essa escrita heteronímica do sentido nomadológico. Essa imanência pressupõe a univocidade do ser como condição da sua construção e é aí que, justamente, as sensações nascem literárias. Nessa ontologia de uma escrita heteronímica, necessariamente fratal, ele é, e tornou-se na prosa de devaneio que escreve. O corpo devém escrita, 
torna-se pura escrita virtual, exprimindo-se através da distribuição de imagens, de intensidades prosódicas ou de ritmos de uma série de palavras que compõem as frases. Ao viver numa lógica de devires, o corpo de Bernardo Soares tornou-se um corpo de escrita num duplo sentido: um corpo escrevente e um corpo escrito, na medida em que a sua puissance de sentir e criar passa também por ser afectada pelos signos do mundo e da vida. Podemos mesmo afirmar que ele construiu, através de agenciamentos do desejo expressivo, e passando por essa ciência do ver e a matemática das sensações, um corpo-sem-órgãos de escrita, corpo esse escrito e fluido, escrevente e consistente. Ele tornou-se e é o plano de consistência do heterogéneo intensivo povoado de multiplicidades, os signos, as sensações e os sonhos. Nesse plano de consistência, o corpo escreve-se heteronimicamente na sua pluralidade constitutiva, ao mesmo tempo que se engendra esse monstruoso corpo-sem-órgãos virtual, composto de multiplicidades diferenciais, os devaneios, os sonhos; os afectos e os perceptos:

Sou, em grande parte, a mesma prosa que escrevo. Desenrolo-me em períodos e parágrafos, faço-me pontuações, e, na distribuição desencadeada das imagens, visto-me como as crianças, de rei com papel de jornal, ou, no modo como faço ritmo de uma série de palavras, me touco, como os loucos, de flores secas que continuam vivas nos meus sonhos. (SOARES, 1998, p. 200)

Para Bernardo Soares, a vida é sobretudo a consciência dela. Com a consciência desperta, ele entrevê, no teatro do ser, o seu exílio ontológico, porque ao devir-outros, ao fragmentar-se, exteriorizando-se, ele separou-se da sua alma, do seu self e da ilusão de uma identidade primeira e originária, substantiva. Tornou-se, assim, uma singularidade nómada, ele que se auto-define como o nómada da consciência de si e o transeunte de tudo. Assim, melhor fora ser o ninguém de todos, a tal case vide qui manque à sa place comme à sa identité, para poder devirimpercetível e, assim, se poder outrar: "Quantas vezes, despertando de mim, não entrevejo, do exílio que sou, quanto fora melhor ser o ninguém de todos..." (SOARES, 1998, p. 200).

No fragmento que estamos comentando, Bernardo Soares insiste no sentido da ontologia da escrita imanente porque, como referimos, há uma relação de imanência imediata entre corpo e linguagem, entre 
um corpo-consciência-sensação-expressão e as sensações literárias ou emoções poéticas: o ser devém-escrita, figura de um livro e uma vida que se lê. O acesso a essa ontologia da expressão, em que o ser é imanente à escrita heteronímica, implica uma génese transcendental das faculdades da alma: ele já sente de modo involuntário e transcendental o sentiendum que se exprime; o que pensa nasce logo com as respectivas palavras, imagens e ritmos; nele, as sensações já nascem literárias. Tornou-se uma multiplicidade diferencial composta pelos seus pensamentos, devaneios e sonhos, ao ponto de perder a identidade una, o self. De tanto se recompor, de tanto pensar, analisar e abstrair das suas sensações; de tanto sonhar e viajar nas sensações, ele destruiu a sua identidade una e desdobrou, qual leque multicolor, nesse palco do ser, o teatro da sua consciência numa pluralidade de figuras virtuais que são os heterónimos. Com os processos da análise microscópica das sensações e da técnica de sonhar, viajando nas sensações verdadeiras, ele forjou uma dobra, um pli na sua consciência, que se tornou um teatro ontológico habitado por uma multidão de atores singulares, a heteronímia virtual soaresiana, ainda não completamente diferenciada como nas Ficções do interlúdio. Com a habitual lucidez e a calculada distância irónica, analisou o seu ser, fez uma profunda autopsicografia, restando-lhe, agora, o olhar o outro rosto de si, a máscara sobreposta a outra máscara, a sua alteridade plural, numa cartografia rizomática do plano de consistência e de coexistência do heterogéneo, em que não há bússola orientadora, mas somente dimensões, linhas de devir e trajetos intensivos.O eu tornou-se uma multiplicidade virtual com os seus dinamismos espácio-temporais e um dispositivo de forças por espelhamento:

Tornei-me uma figura de livro, uma vida lida. O que sinto é (sem que eu o queira) sentido para se escrever que se sentiu. O que penso está logo em palavras, misturado com imagens que o desfazem, aberto em ritmos que são outra coisa qualquer. De tanto recompor-me, destruí-me. De tanto pensar-me, sou já meus pensamentos mas não eu. Sondei-me e deixei cair a sonda; vivo a pensar se sou fundo ou não, sem outra sonda agora senão o olhar que me mostra, claro a negro no espelho do poço alto, meu próprio rosto que me contempla contemplá-lo. (SOARES, 1998, p. 201). 
Ao insistir numa caracterização autopsicográfica pós-moderna da sua singularidade como diferença absoluta, descreve-se como uma carta de jogar única, metáfora literal do jogo ontológico, autêntico teatro do ser, ao qual assiste, jogo ideal de singularidades e multiplicidades virtuais, que são os heterónimos latentes, as suas visões e os afectos. Nesse jogo ideal do pensamento e da criação, há lugar para o acaso e o aleatório. Contudo, cada lance é necessariamente vencedor, porque cria as suas próprias regras, isto é, o movimento imanente de composição do Livrorizoma com os seus próprios nexos, determinados por uma necessidade e uma coerência mais secreta e profunda que o falso movimento da lógica e da dialética hegeliana: "Sou uma espécie de carta de jogar, de naipe antigo e incógnito, restando única do baralho perdido." (SOARES, 1998, p. 200).

Deste modo, vai descrevendo, em imagens, a sua singularidade e diferença absoluta, como um ser de escrita, ser ficcional, cuja substância é composta por palavras, frases, imagens e ritmos. A escrita heteronímica virtual criou a monstruosidade prodigiosa do drama em gente sem actos, dramas interactivos em almas. Trata-se, neste sentido, de afirmar a radical ficcionalidade pós-moderna do sujeito poético plural e escrevente na sua relação de imanência com a escrita necessariamente heteronímica:

E assim, em imagens sucessivas em que me descrevo não sem verdade, mas com mentiras -, vou ficando mais nas imagens do que em mim, dizendo-me até não ser, escrevendo com a alma como tinta, útil para mais nada do que para se escrever com ela. (SOARES, 1998, p. 201).

Neste contexto de pós-modernidade avant la lettre, afirma também a ficção no cerne da sua substância ontológica. A vida autêntica e real para ele é o sonho e a ficção. A ficção ou criação fabuladora de mundos e dramas compostos de almas interactivas é a dimensão virtual mais presente e intensa que dá sentido à sua existência nomadológica. Nessa dimensão, exprime a sua mais radical singularidade: a ficção acompanha-o como a sua sombra e viver é ser outro. E, como sabemos, essa dimensão virtual composta de sensações e sonhos, afetos e perceptos, atualiza-se, imediatamente, na consciência do sonhador larvar e no plano da expressão escrita. Só um sujeito pós-moderno e larvar, plástico, fluido e intenso, como Bernardo Soares, é capaz de suportar os tais 
dinamismos espácio-temporais, implicados no processo de actualização das multiplicidades virtuais (sensações, emoções poéticas e sonhos; afectos e perceptos): "A ficção acompanha-me como a minha sombra." (SOARES, 1998, p. 201).

Lisboa e Barcelos, Verão-Outono de 2015.

\section{Referências}

\section{Bibliografia activa}

PESSOA, Fernando. Teoria da heteronímia. Edição de Fernando Cabral Martins e Richard Zenith. Lisboa: Assírio \& Alvim, 2012.

PESSOA, Fernando. Sobre Orpheu e o sensacionismo. Edição de Fernando Cabral Martins e Richard Zenith. Lisboa: Assírio \& Alvim, 2015.

SOARES, Bernardo. Livro do desassossego. Lisboa: Assírio \& Alvim, 1998. (1 ${ }^{\text {a }}$ Edição de Richard Zenith).

DELEUZE, Gilles. Différence et Répétition. Paris: PUF, 1997a.

DELEUZE, Gilles. Logique du sens. Paris: Editions de Minuit, $1997 \mathrm{~b}$.

DELEUZE, Gilles; GUATTARI, Felix. Mille Plateaux. Paris: Editions de Minuit, 1994.

DELEUZE, Gilles; GUATTARI, Felix. Rizoma. Trad. Rafael Godinho. Lisboa: Assírio \& Alvim, 2006.

DELEUZE, Gilles; GUATTARI, Felix. Qu'est-ce la philosophie? Paris: Editions de Minuit, 2011.

\section{Bibliografia passiva}

EIRAS, Pedro. Esquecer Fausto, A fragmentação do sujeito em Raul Brandão, Fernando Pessoa, Herberto Helder e Maria Gabriela Llansol. Porto: Campo das Letras, 2005.

GIL, José. Fernando Pessoa ou a Metafísica das Sensações. Lisboa: Relógio D’Água, 1987. 
GIL, José. O Espaço Interior. Lisboa: Presença, 1994.

GIL, José. Diferença e Negação na Poesia de Fernando Pessoa. Lisboa: Relógio D’Água, 1999.

GIL, José. Deleuze: Esthétique, littérature, ontologie. In: GELAS, Bruno; MICOLET, Hervé (Dir.). Deleuze et les écrivains. Littérature et philosophie. Nantes: Éditions Cécile Defaut, 2007.

GIL, José. O devir-eu de Fernando Pessoa. Lisboa: Relógio D’Água Editores, 2010.

GIL, José. Cansaço, Tédio, Desassossego. Lisboa: Relógio D’Água Editores, 2013.

HARVEY, David. Condição pós-moderna. Uma pesquisa sobre as origens da mudança cultural. São Paulo: Edições Loyola, 1992.

LOPES, Terena Rita. Fernando Pessoa et le Drame Symbolista: Heritage et Création. Paris: Fondation Caloustre Gulbenkian, Centre Culturel Portugais, 1985.

LOURENÇO, Eduardo. Fernando Rei da nossa Baviera. Lisboa: INCM, 1993.

LOURENÇO, Eduardo. Pessoa revisitado. Lisboa: Gradiva, 2003.

LOURENÇO, Eduardo. O lugar do Anjo. Lisboa: Gradiva, 2004.

SENA, Jorge de. Fernando Pessoa \& C. ${ }^{a}$ Heterónima. Estudos coligidos 1940-1978. Lisboa: Edições 70, 1982. v. I. 